\title{
EFFECT OF COOLING RATE ON GLEEBLE HOT DUCTILITY OF UDIMET ALLOY 720 BILLET
}

\author{
M. Fahrmann ${ }^{1}$ and A. Suzuki ${ }^{2}$ \\ ${ }^{1}$ Special Metals Corporation, 3200 Riverside Drive, Huntington, WV 25705, USA \\ ${ }^{2}$ GE Global Research, 1 Research Circle, Niskayuna, NY 12309, USA
}

Keywords: UDIMET alloy 720, billet, hot ductility, cooling rate, gamma prime, microtwinning

\begin{abstract}
Conversion of highly-alloyed $\gamma$ '-hardened disk alloys such as UDIMET alloy 720 from cast ingot into billet requires a detailed knowledge of the hot working process window. Hot workability of billet stock was assessed by Gleeble tension testing. The effects of test temperature and, in particular, cooling rate from the prior annealing temperature to the test temperature on hot ductility were systematically studied. High cooling rates on the order of 30 ${ }^{\circ} \mathrm{C} / \mathrm{s}$ as realized in the Gleeble tester resulted in a dramatic drop in hot ductility. Much slower cooling rates, representative of industrial conversion operations, resulted in acceptable ductility of greater than $60 \%$. Microstructures of the as-supplied billet stock and in the various tested conditions were characterized. The measured significant differences in hot ductility are rationalized by the dominant deformation mechanisms observed microscopically.
\end{abstract}

\section{Introduction}

UDIMET alloy 720, a $\gamma^{\prime}$-hardenable Ni-base superalloy, is known to be one of the highest alloyed disk materials that can be processed along the traditional cast \& wrought route [1]. Thermomechanical conversion of the cast ingot to billet stock is often accomplished by press forging at temperatures approximately 50 ${ }^{\circ} \mathrm{C}$ below the $\gamma^{\prime}$-solvus temperature (roughly $1160{ }^{\circ} \mathrm{C}$ ). Owing to the rapid age hardening propensity of this alloy upon cooling while being processed, loss of ductility is a major concern potentially impacting quality and yield.

Hot ductility of billet stock is traditionally assessed by various types of Gleeble hot deformation testing schemes that reflect the relatively high strain rates encountered in industrial conversion operations. In the present study, simple Gleeble tension testing was executed. To closely simulate conversion processes, the specimens were heated to a nominal forging temperature, stabilized, and then cooled within a wide range of rates to the actual test temperature. Reduction in area was utilized as a measure of hot ductility. These tests were complemented by detailed analyses of the respective microstructures.

\section{Experiment}

Material was made available from $0.15 \mathrm{~m}$ diameter billet. The actual chemical composition of this billet stock is listed in Table I. Two alloying elements ( $\mathrm{Cr}$ and $\mathrm{Ti}$ ) are slightly outside the specification limits for UDIMET alloy 720. This resulted in a $\gamma^{\prime}-$ solvus temperature elevated by roughly $10{ }^{\circ} \mathrm{C}$ over regular production material. Nonetheless, it is believed that the results and conclusions of this study are generally applicable to highly alloyed $\gamma$ '-hardened disk materials.

Table I. Chemical composition (in wt.\%) of the studied billet material.

\begin{tabular}{|c|c|c|c|c|c|c|c|}
\hline $\mathbf{C}$ & $\mathbf{C r}$ & $\mathbf{M o}$ & $\mathbf{W}$ & $\mathbf{A l}$ & $\mathbf{T i}$ & $\mathbf{C o}$ & $\mathbf{N i}$ \\
\hline 0.013 & 14.8 & 3.1 & 1.3 & 2.7 & 5.5 & 14.2 & bal. \\
\hline
\end{tabular}

Uniformity of the microstructure across the billet diameter was adequate to allow for machining of a significant number of Gleeble specimens without regard to location. All specimens featured an axial orientation. Specimens were mounted in a Gleeble tester, rapidly annealed to a temperature of $1110^{\circ} \mathrm{C}$, and held for $5 \mathrm{~min}$. Cooling rates to the actual test temperature varied between 0.03 and $30{ }^{\circ} \mathrm{C} / \mathrm{s}$. The upper bound reflects cooling rates typically encountered in Gleeble tests whereas the lower bound approximates cooling rates experienced by the billet center upon a standard air cool [2].

Once stabilized (1 min) at the test temperature, specimens were pulled rapidly at approximately $0.02 \mathrm{~m} / \mathrm{s}$ translating into strain rates on the order of $1 / \mathrm{s}$. Peak loads were used to compute tensile strength, and reduction of area was employed as a measure of hot ductility.

Microstructures of the material in the as-supplied as well as in the various tested conditions were characterized by optical microscopy, SEM, and TEM. Seven-acids etch $(300 \mathrm{ml}$ hydrochloric acid, $60 \mathrm{ml}$ nitric acid, $60 \mathrm{ml}$ phosphoric acid, $30 \mathrm{ml}$ hydrofluoric acid, $30 \mathrm{ml}$ sulfuric acid, 30 grams anhydrous iron chloride, $60 \mathrm{ml}$ acetic acid, $300 \mathrm{ml}$ water) was employed to reveal the $\gamma^{\prime}$ precipitates. In order to gain insight into the operative deformation mechanisms during testing, TEM specimens were prepared from near the fracture surfaces. Discs $0.12 \mathrm{~mm}$ in thickness and $3 \mathrm{~mm}$ in diameter were cut, mechanically polished, and then subjected to twin-jet electron polishing in a solution of $340 \mathrm{ml}$ methanol, $50 \mathrm{ml}$ perchloric acid, $65 \mathrm{ml}$ butyl cellusolve and $45 \mathrm{ml}$ distilled water. The polishing was conducted at $-40{ }^{\circ} \mathrm{C}$ and a voltage of $18 \sim 22 \mathrm{~V}$.

\section{Results and Discussion}

Fig. 1 shows reduction of area (RA) as a function of test temperature for standard Gleeble testing conditions, i.e., cooling rates of approximately $30{ }^{\circ} \mathrm{C} / \mathrm{s}$. The two curves represent the test results obtained with two sets of specimens and demonstrate the reproducibility of the results. The dramatic drop in hot 
ductility at around $1040{ }^{\circ} \mathrm{C}$ is apparent. Values of less than $20 \%$ in RA are generally considered unacceptable for hot forming operations. Recalling that billet surface temperatures could readily drop below this mark during a forge session, major surface cracking could be anticipated. This projection contradicts forge shop experience with this alloy.

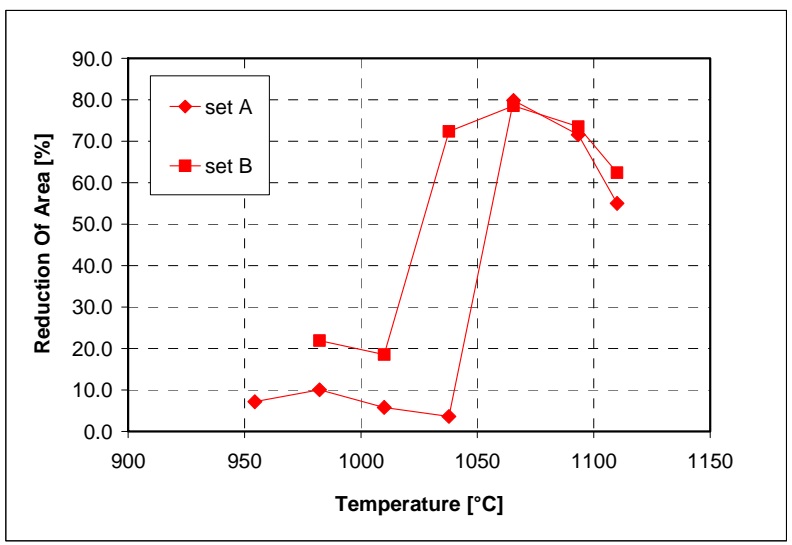

Figure 1. Reduction of area as a function of test temperature of two sets of specimens. Standard Gleeble testing conditions.

Another set of specimens was subsequently tested employing a cooling rate of only $0.03^{\circ} \mathrm{C} / \mathrm{s}$ to the test temperature. The results are plotted in Figure 2 and contrasted to the outcome of the first test condition employing a cooling rate of $30{ }^{\circ} \mathrm{C} / \mathrm{s}$.

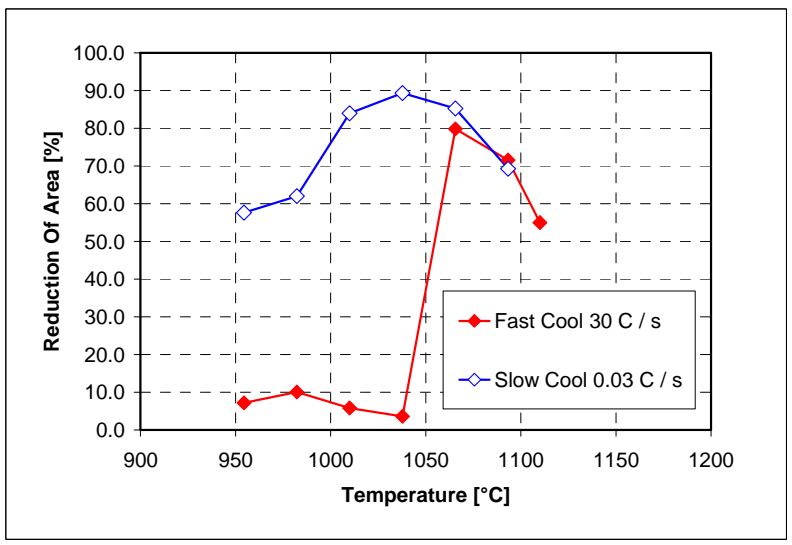

Figure 2. Reduction of area as a function of test temperature for two different cooling rates of $30{ }^{\circ} \mathrm{C} / \mathrm{s}$ and $0.03{ }^{\circ} \mathrm{C} / \mathrm{s}$.

Evidently, the drop in hot ductility is no longer present. Ductility over a wide temperature range is quite acceptable, actually suggesting a generous hot working window.
To further explore cooling rate effects, another set of specimens was cooled at varying rates to $1010{ }^{\circ} \mathrm{C}$, and pulled. Figure 3 depicts the measured RA values as a function of cooling rate. Superimposed on this graph is the range of cooling rates from center to surface modeled for air cooling of an intermediate size, $0.38 \mathrm{~m}$ diameter billet [2]. Apparently, even the billet surface can be expected to exhibit sufficient hot ductility.

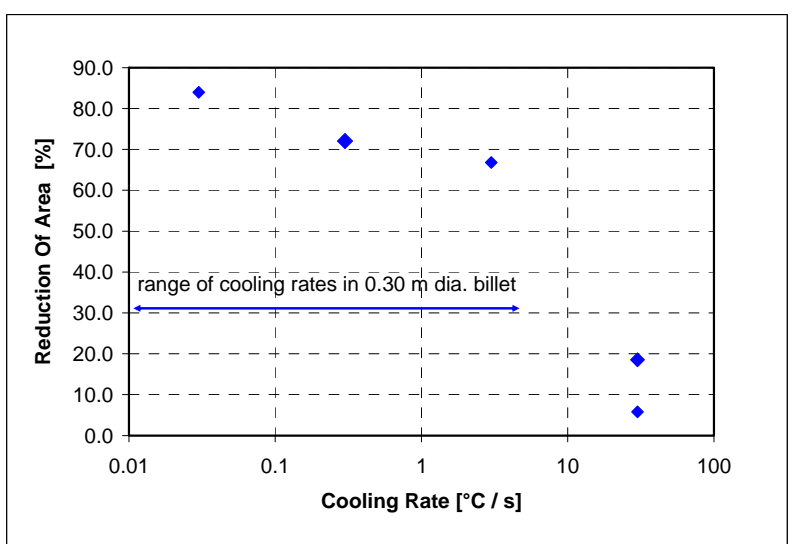

Figure 3. Reduction of area as a function of cooling rate to a test temperature of $1010^{\circ} \mathrm{C}$. Superimposed is the modeled range of cooling rates of aircooled $0.38 \mathrm{~m}$ diameter billet.

Hence, from a conversion point of view, hot cracking should be a rare event. However, above reasoning does not account for the fact that the grain structure of the tested material (fully wrought) is certainly not representative of the grain structure during initial ingot break-down. It is speculated that the initially coarse, oriented grain structure in the cast ingot may be much more important in terms of cracking propensity than any lack of traditional Gleeble hot ductility measured on fully wrought, finegrained material. This notion is supported by shop floor observations in that the workability of UDIMET alloy 720 billet generally improves throughout the conversion process [3].

In order to gain insight into the different hot ductility behaviors, microstructures of material in the initial and selected tested conditions were examined. Specifically, samples from the standard test runs at $30{ }^{\circ} \mathrm{C} / \mathrm{s}$ (subsequently referred to as "fast cooling" condition) and $0.03{ }^{\circ} \mathrm{C} / \mathrm{s}$ (referred to as "slow cooling" condition) were chosen for detailed analyses. Test temperature was $1010{ }^{\circ} \mathrm{C}$ in either case.

Figure 4 depicts the typical as-supplied microstructure featuring coarse, blocky primary $\gamma$ ' precipitates of several microns in size. The grain size was read to ASTM 8 or finer. Higher magnification images (Figure 5) revealed the presence of $150 \mathrm{~nm}$ size fine spherical secondary $\gamma$ ' that must have formed during cooling from the hot working temperature. It can be expected that this fine cooling $\gamma^{\prime}$ would dissolve upon heating to the $1110{ }^{\circ} \mathrm{C}$ annealing temperature in the Gleeble tester. 


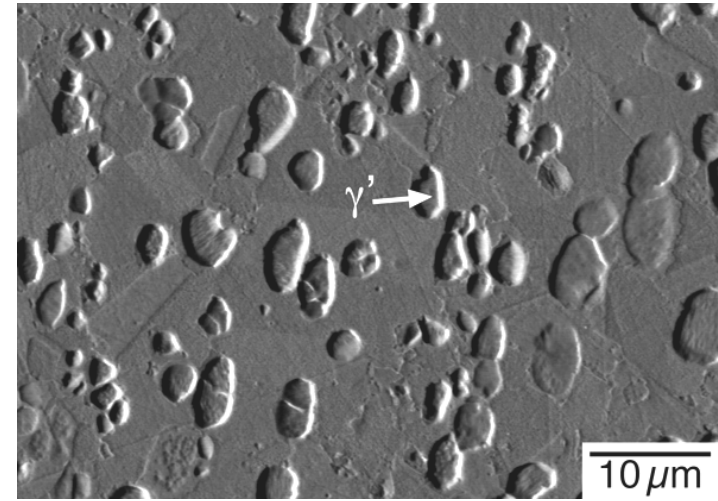

Figure 4. SEM micrograph of the as-supplied billet microstructure featuring coarse, blocky primary $\gamma^{\prime}$.

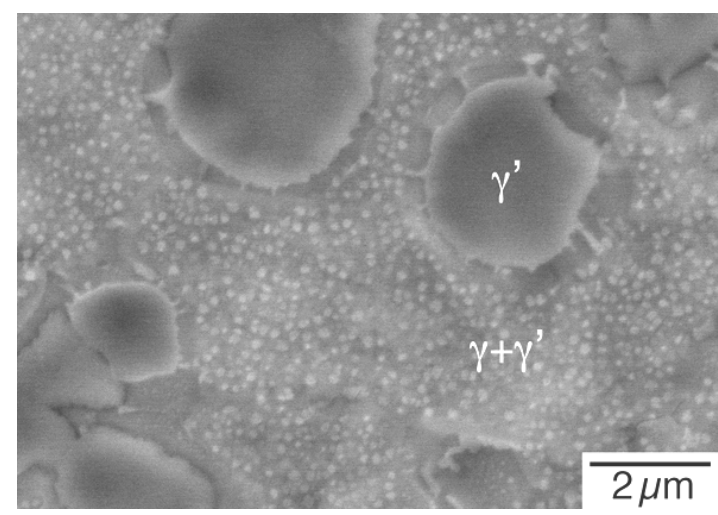

Figure 5. SEM micrograph of the as-supplied billet microstructure revealing fine cooling $\gamma^{\prime}$.

A SEM micrograph representative of the "fast cooling" condition is shown in Figure 6. Notice the presence of the similarly coarse blocky $\gamma^{\prime}$ as observed in the as-supplied condition (Figure 4). Evidently, the $1110{ }^{\circ} \mathrm{C}$ annealing temperature in the Gleeble tester was well below the $\gamma^{\prime}$-solvus temperature of the material as intended.

A higher resolution TEM micrograph (Figure 7) revealed copious amounts of fine, approximately $40 \mathrm{~nm}$-size secondary $\gamma$ ' that precipitated during controlled cooling from the $1110{ }^{\circ} \mathrm{C}$ annealing temperature to the $1010{ }^{\circ} \mathrm{C}$ test temperature.

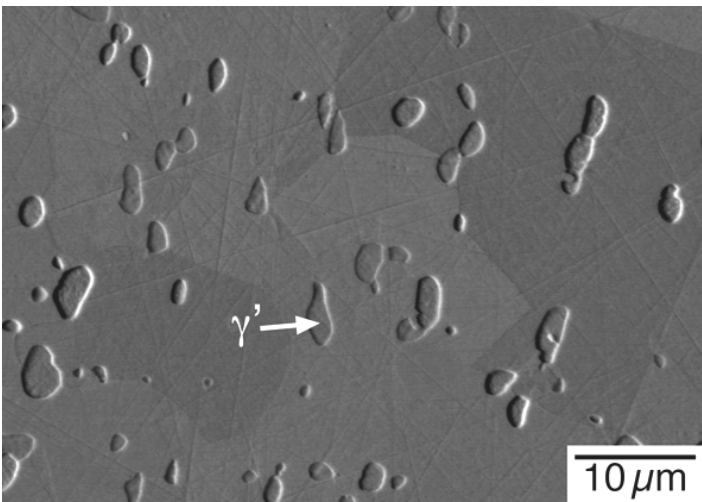

Figure 6. SEM micrograph of the gage section of a Gleeble specimen in the "fast cooling” condition.

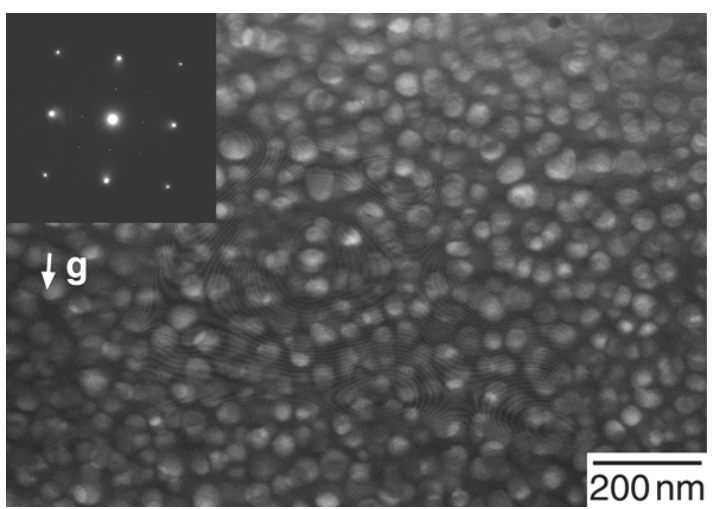

Figure 7. TEM dark field image of "fast cooling" specimens featuring copious amounts of secondary $\gamma^{\prime}$ precipitates in $\gamma$ matrix $(\mathbf{B}=001, \mathbf{g}=100)$.

In order to examine the deformation mechanisms operative during Gleeble tests, TEM foils were prepared from near the fracture surface. A bright field image (Figure 8a) exhibits a high density of planar faults with a couple of $100 \mathrm{~nm}$ in spacing. These faults are continuous across entire grains. The diffraction pattern taken from the [011] direction shows weak reflection spots that have a twin relationship with the matrix as indicated with circles. A higher magnification micrograph (Figure 8b) shows thin twin plates $10-30 \mathrm{~nm}$ thick. The twin interfaces are indicated with arrowheads, and they are (111) planes. The twin plates seem to penetrate $\gamma^{\prime}$ precipitates. Other deformation activities, such as dislocation gliding, are rarely observed in this specimen. These features are similar to "microtwins" observed in polycrystalline Ni-base superalloys with fine $\gamma^{\prime}$ precipitates during creep deformation at low temperature and high stress condition [4]. Therefore, microtwinning is surmised to be the dominant deformation mechanisms in the "fast cooling" condition. 


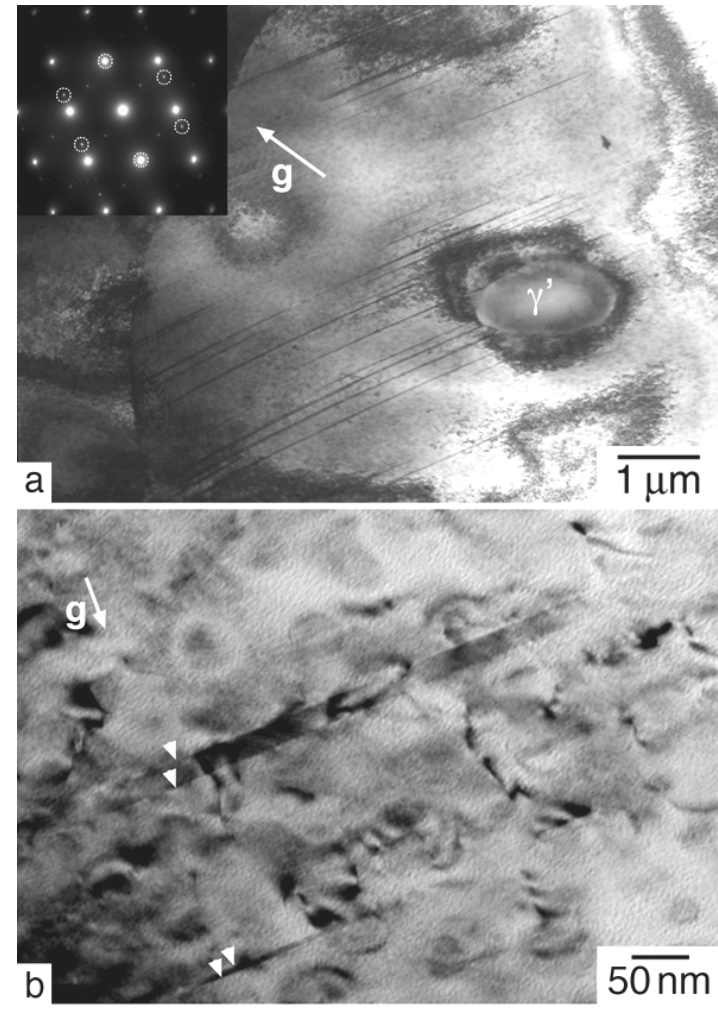

Figure 8. TEM bright field images of the region near fracture surface of Gleeble specimens in the "fast cooling" condition, showing microtwins $(\mathbf{B}=011)$.

A SEM micrograph representative of the "slow cooling" condition is shown in Figure 9. In addition to the retained primary coarse $\gamma^{\prime}$, secondary $\gamma^{\prime}$ of dendritic morphology is evident. Such morphologies are likely growth morphologies as reported in a number of $\gamma^{\prime}$-hardened alloys. They typically result from slow cooling (on the order of $1{ }^{\circ} \mathrm{C} / \mathrm{min}$ ) through the $\gamma^{\prime}$ precipitation range [5]. In the present study, they are surmised to have formed during slow cooling from the $1110{ }^{\circ} \mathrm{C}$ annealing temperature to the $1010{ }^{\circ} \mathrm{C}$ test temperature. Precipitate-free zones around the primary $\gamma$ ' precipitates are also apparent, indicative of the exhausted hardener levels in the vicinity of these larger particles.

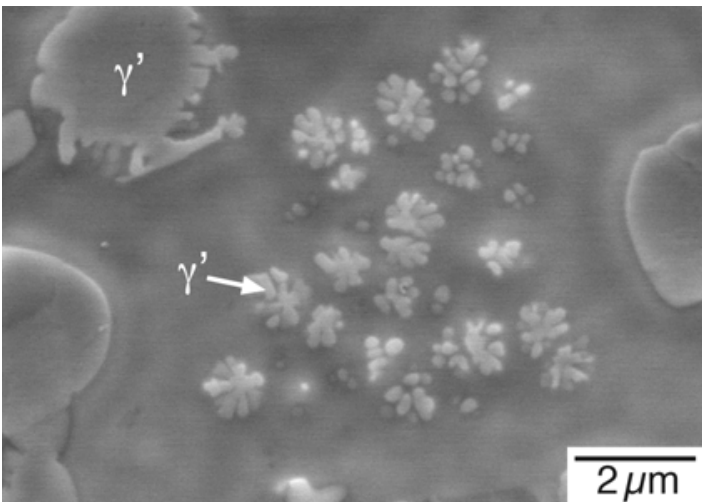

Figure 9. SEM micrograph of the gage section of Gleeble specimens in the "slow cooling" condition.
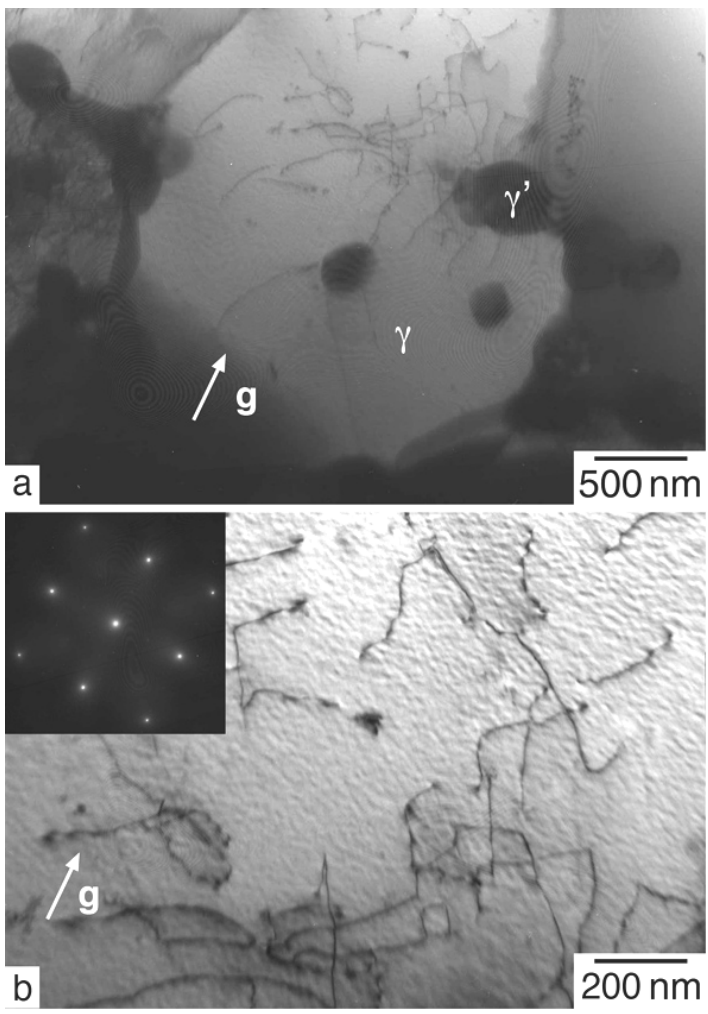

Figure 10. TEM bright field images of the region near fracture surface of Gleeble specimens in the "slow cooling" condition $(\mathbf{B}=001)$.

Figure 10(a) shows a TEM bright field image taken from near fracture surface of the specimen in "slow cooling" condition. Large $\gamma$ ' precipitates with a size larger than $200 \mathrm{~nm}$ are present in the $\gamma$ matrix. Different from the "fast cooling" condition, microtwins were absent. Instead, dislocations gliding in the matrix phase were observed (Figure 10(b)). They were identified as $1 / 2<110>$ type dislocations via $\mathbf{g} \cdot \mathbf{B}$ analysis. Therefore, normal 
dislocation gliding appears to be the dominant deformation mechanism in the "slow cooling" condition.

Based on the examinations of the various microstructures, the Gleeble results can be rationalized. Upon cooling from the 1110 ${ }^{\circ} \mathrm{C}$ annealing temperature to the actual test temperature, a significant supersaturation of the $\gamma$-matrix in the $\gamma$ '-forming elements $\mathrm{Al}$ and $\mathrm{Ti}$ will build up (Figure 11).

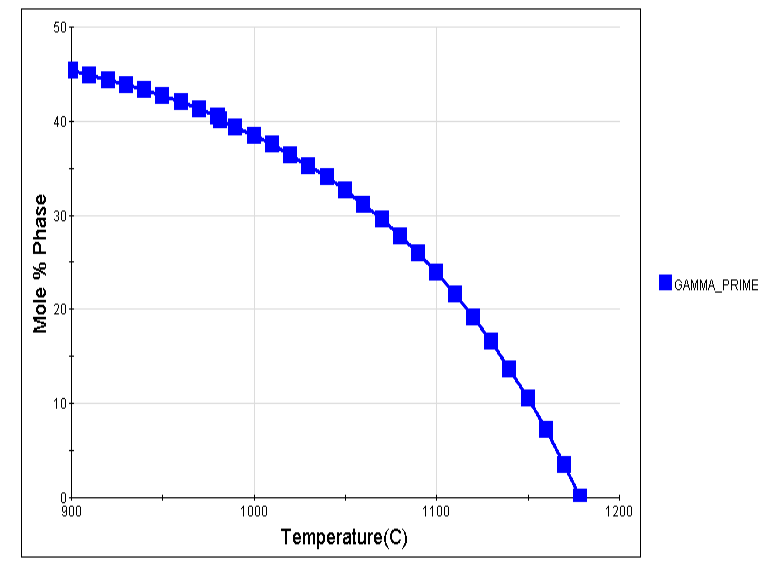

Figure 11. JMatPro predictions [6] of the temperature-dependent $\gamma$ ' volume fraction in the studied billet material.

Then, the cooling rate dictates the interplay between nucleation of secondary $\gamma^{\prime}$ and its growth - high cooling rates favor nucleation, hence, large amounts of very fine secondary $\gamma$ ' precipitates are formed. Their size and tight spacing greatly impede dislocation motion during the actual Gleeble test. In $\gamma+\gamma^{\prime}$ alloys, mode of $\gamma^{\prime}$ shearing depends on the size of precipitates. Generally, when precipitates are small (less than $100 \mathrm{~nm}$ ), the precipitates are sheared by $1 / 6<112>$ partial dislocations, rather than $1 / 2<110>$ dislocations, and microtwins [4] or stacking faults [7] are observed. This is thought to be the case of the "fast cooling" condition. Interestingly, it apparently takes a significant amount of supersaturation (or undercooling) in solute for this mechanism to become operative since the ductility deficit did not materialize for small amounts of undercooling (see Figure 1).

In the "slow cooling" case, precipitate growth (either of preexisting, retained primary $\gamma$ ' or newly created secondary $\gamma$ ' nuclei) dominates. Hence, nucleation number densities are low and precipitate spacing is significantly greater. Such microstructures enable the classical $(111)<110>$ slip systems in the $\gamma$ matrix, and result in much improved ductility.

The ramifications of the different microstructures for specimen mechanical behavior are also reflected in their tensile strengths fine secondary $\gamma^{\prime}$ resulted in significantly higher strength levels than coarser dendritic secondary $\gamma^{\prime}$ (Figure 12).

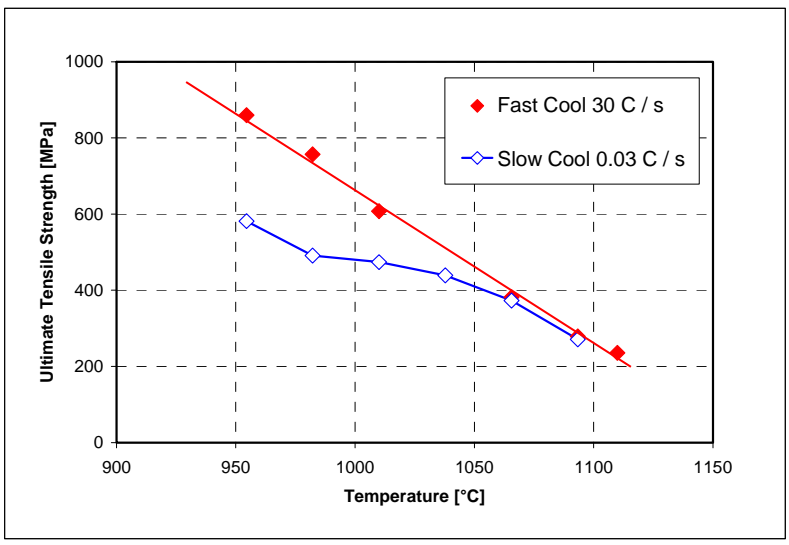

Figure 12. Gleeble tensile strengths as a function of test temperature for "fast cooling" and "slow cooling" testing regimes.

Above reasoning should be generally applicable to highly alloyed Ni-base superalloys that exhibit a sufficient variation in $\gamma^{\prime}$ volume fraction within the hot working window. Indeed, quite similar debits in hot ductility were reported for UDIMET alloy 700 in the "fast cooling" condition [8].

\section{Summary and Conclusions}

Hot workability of highly-alloyed $\gamma$ '-hardened billet stock of UDIMET alloy 720 type was assessed by Gleeble testing. Gleeble hot ductility was found to be sensitive to cooling rate from the prior annealing temperature. High cooling rates on the order of $30{ }^{\circ} \mathrm{C} / \mathrm{s}$ resulted in poor ductility of less than $20 \%$. Lower cooling rates of $3{ }^{\circ} \mathrm{C} / \mathrm{s}$ or less resulted in ductility exceeding $60 \%$

The observed differences in hot ductility could be rationalized by the precipitation kinetics of $\gamma^{\prime}$ during cooling from the prior annealing temperature to the actual test temperature. High cooling rates caused very fine, $40 \mathrm{~nm}$-size secondary $\gamma^{\prime}$ which triggered micro-twinning in the course of Gleeble testing. In contrast, slow cooling yielded much coarser (even dendritic) secondary $\gamma$ ' that enabled the classical $(111)<110>$ slip.

As for industrial conversion operations, it seems that even surface chill rates would ordinarily fall into the slow cooling regime. Hence, lack of workability is likely be caused by factors other than $\gamma^{\prime}$ precipitation kinetics.

\section{Acknowledgment}

The authors would like to thank Mr. Steve Gosnay (Special Metals Corp.) for conducting the Gleeble tests and Prof. Tresa Pollock (University of Michigan) for supporting the microscopy work. 


\section{References}

[1] D. J. Bryant and G. McIntosh, "The manufacture and evaluation of a large turbine disc in cast and wrought alloy 720LI", Proceedings of the Eighth International Symposium on Superalloys, ed. R. D. Kissinger et al., (TMS, 1996), 713 - 722.

[2] Ch. Rock, personal communication with author, Special Metals Corporation, 2006.

[3] D. Borowski, personal communication with author, Special Metals Corporation, 2007.

[4] G.B. Viswanathan, P.M. Sarosi, M.F. Henry, D.D. Whitis, W.W. Milligan, and M.J. Mills, "Investigation of creep deformation mechanisms at intermediate temperatures in René 88 DT," Acta Mater., 53 (2005), 3041-3057.

[5] M. F. Henry, Y. S. Yoo, D. Y. Yoon, and J. Choi, "The dendritic growth of g' precipitates and grain boundary serration in a model Ni-base superalloy” Met. Trans., 24A (1993) 1733 1738.

[6] N. Saunders, Z. Guo, X. Li, and J.-Ph. Schille, JOM, 55 (2003), 60.

[7] S. Shinharoy, P. Virro-Nic, and W.W, Milligan, "Deformation and Strength Behavior of Two Nickel-Base Turbine Disk Alloys at $650^{\circ} \mathrm{C}, "$ Metall. Mater. Trans., 32A (2001), 2021-2032.

[8] L. A. Jackman and T. P. Dressel, "Hot workability of U-720 as determined by Gleeble testing” (Report TR-78-003, Special Metals, 1978). 